\title{
Assessment of endoscopic retrograde cholangio- pancreatography (ERCP) and pure pancreatic juice cytology in patients with pancreatic disease
}

\author{
A. R. W. HATFIELD ${ }^{1}$, A. SMITHIES, R. WILKINS, AND A. J. LEVI \\ From Northwick Park Hospital and Clinical Research Centre, Middlesex
}

SUMMARY Pure pancreatic juice has been collected from 61 patients at the time of endoscopic retrograde cholangio-pancreatography (ERCP) for the purpose of cytodiagnosis. The ERCP and cytological findings are discussed. Pure pancreatic juice cytology may help in the interpretation of the pancreatogram in both pancreatitis and pancreatic carcinoma. In patients with pancreatic carcinoma, ERCP alone was diagnostic in $65 \%$, cytology alone in $54 \%$. By combining these two approaches, a diagnostic result was obtained in $92 \%$ of patients.

The introduction of ERCP to Great Britain in the last four years has been a major advance in the investigation of pancreatic and biliary disease (Cotton, 1972). This investigation is both practical and safe, but there can be considerable difficulties in the interpretation of the pancreatogram.

Although the exfoliative cytology of duodenal aspirates for the diagnosis of pancreatic disease has been practised since 1949 (Lemon and Byrnes, 1949), it has not become a routine investigation. Duodenal intubation and drainage are time consuming and there are major difficulties in the interpretation of the cytological findings.

Using the technique of endoscopic cannulation of the papilla of Vater, it has been possible to collect pure juice directly from the pancreatic duct for the purpose of cytodiagnosis.

In this study, pure pancreatic juice was collected at the time of ERCP and the value of this combined diagnostic approach is assessed in patients with and without pancreatic disease.

\section{Methods}

\section{TECHNIQUE}

ERCP was performed in the usual way, using an Olympus JF-B duodenoscope on patients lightly sedated with intravenous diazepam. The procedure was undertaken in the $x$-ray department under fluoroscopic control, using $65 \%$ Angiograffin con-

'Present address and for correspondence: Academic Unit of Gastro-
enterology, The London Hospital, Whitechapel, London, E1 1BB.

Received for publication 23 October 1975 trast medium. In two-thirds of the patients studied, pancreatic juice was collected before the injection of contrast medium.

Pancreatic juice was collected in all but two patients using the following two methods.

Method 1 The cannula was inserted through the papilla of Vater into the pancreatic duct to a depth of $2-3 \mathrm{~cm}$.

Method 2 In patients where the cannula failed to enter the pancreatic duct, juice was collected from the orifice of the papilla of Vater.

In two patients where neoplastic involvement of the duodenum made location of the papilla of Vater impossible, pancreatic juice was collected from the lumen of the duodenum.

A stimulus for pancreatic secretion was found to be necessary before juice could be collected from within the pancreatic duct. In this study, a single intravenous injection of Boots secretin was given at a dose of 1 unit/kg body weight. In most patients a flow of juice through the cannula was obtained. If this flow were poor, gentle aspiration with a syringe was needed. Five $1 \mathrm{ml}$ samples of pancreatic juice were collected for cytological examination at 0,5 , 10,15 , and 20 minutes after secretin stimulation.

At the end of the pancreatic juice collection, the samples were taken immediately to the cytology department where each was spun at 1500 r.p.m. using a cytocentrifuge. In this way, the cells are deposited in a discrete circle on the slide, presenting a compact area, facilitating cytological screening. The slides were stained with Papanicolaou stain. 


\section{PATIENTS}

A total of 61 patients were included in this study. These patients were all undergoing investigations for suspected pancreatic and biliary disease. Twentysix of these patients were finally judged to have no detectable pancreatic disease, as evidenced by a normal Lundh test, normal serum amylase levels, no radiological evidence of abdominal calcification, and clinical follow-up of between four and 18 months.

Nine patients had pancreatitis, five with relapsing pancreatitis, and four with chronic pancreatitis. The five patients with relapsing pancreatitis had all experienced at least two attacks of acute pancreatitis diagnosed clinically, with serum amylase values on each occasion rising above 1000 Somogyi units; in two the diagnosis was confirmed at laparotomy and radiological evidence of pancreatic calcification was seen in a further one patient. The four patients with chronic pancreatitis had abnormal Lundh tests, with mean trypsin levels of below $2 \mathrm{IU} / 1$, and radiological evidence of pancreatic calcification was seen in two patients.

Twenty-six patients had pancreatic carcinoma; in 22 of these the diagnosis was confirmed at laparotomy, and in the remaining four at necropsy. In no patient was the tumour considered resectable at the time of laparotomy.

The ERCP findings were in no way taken into account when considering the final diagnosis in any of these patients.

\section{Results}

\section{ERCP FINDINGS}

\section{Normal group}

A pancreatogram was obtained in 25 out of 26 patients in this group. In all these 25 patients the radiological findings were considered to be within normal limits (Fig. 1). In some of these patients minor side duct irregularities and small cysts of less than $2 \mathrm{~mm}$ in diameter were seen (Fig. 2); these were considered to be the results of the normal ageing process. The biliary system was outlined in 17 of the 26 patients.

\section{Pancreatitis group}

In this group of nine patients a pancreatogram was obtained in eight. Changes compatible with pancreatitis were seen in six of these patients (Fig. 3). In seven patients the biliary system was demonstrated.

\section{Pancreatic carcinoma group}

A pancreatogram was obtained in 20 of the 26 patients in this group. In 18 of these the radiological changes seen were considered diagnostic of carcinoma (Fig. 4), and in two patients the changes were only suggestive of carcinoma. A normal pancreatogram was never obtained in any of the patients in this group. Endoscopic evidence of neoplastic involvement of the duodenum was obtained in only

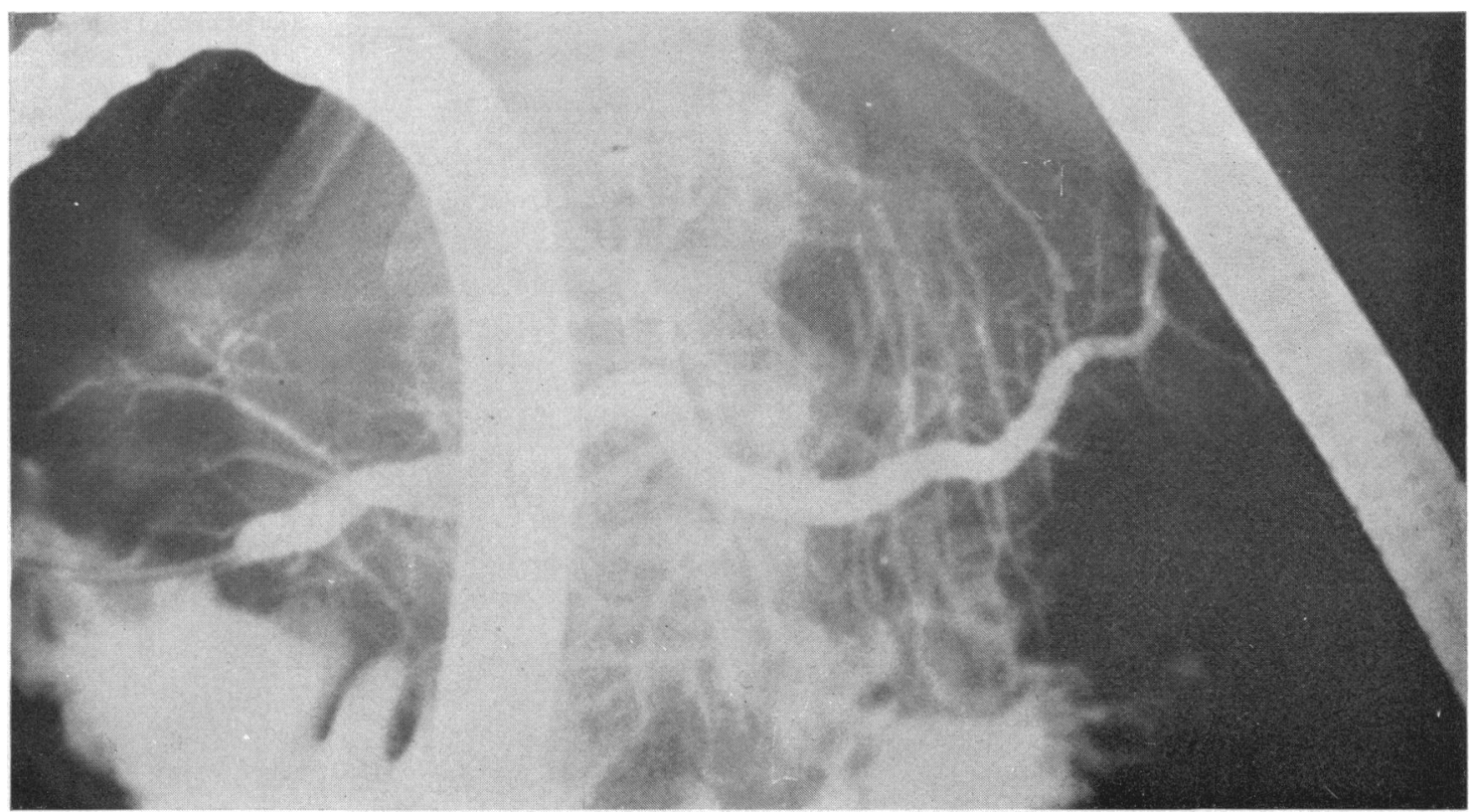

Fig. 1 The normal pancreatogram. 


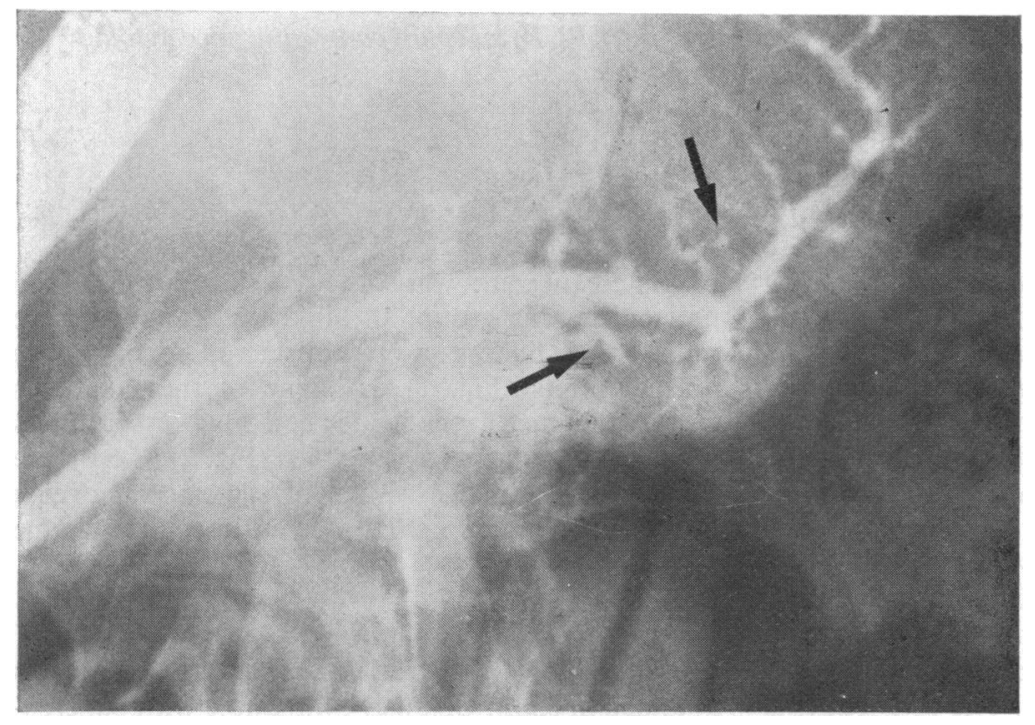

Fig. 2 A pancreatogram in a woman aged 76 years with no detectable pancreatic disease. There are some small cysts and minor side duct irregularities (arrowed) compatible with her age.

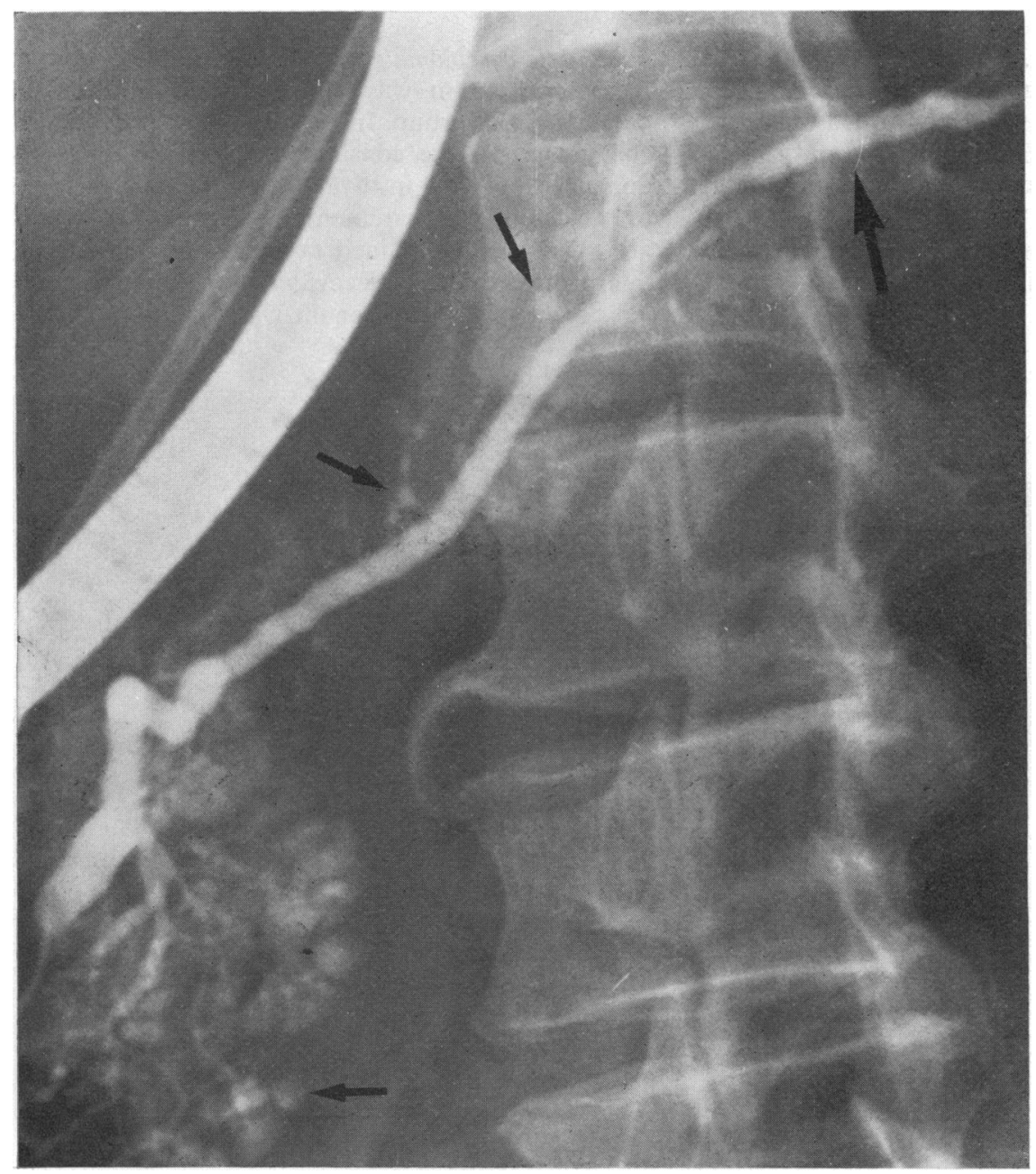

Fig. 3 A pancreatogram in a man 68 years with relapsing pancreatitis. There is irregularity in the main pancreatic duct (large arrow) together with cysts and side duct irregularities (small arrows). Coarse acinar filling occurred at an early stage of contrast injection. 


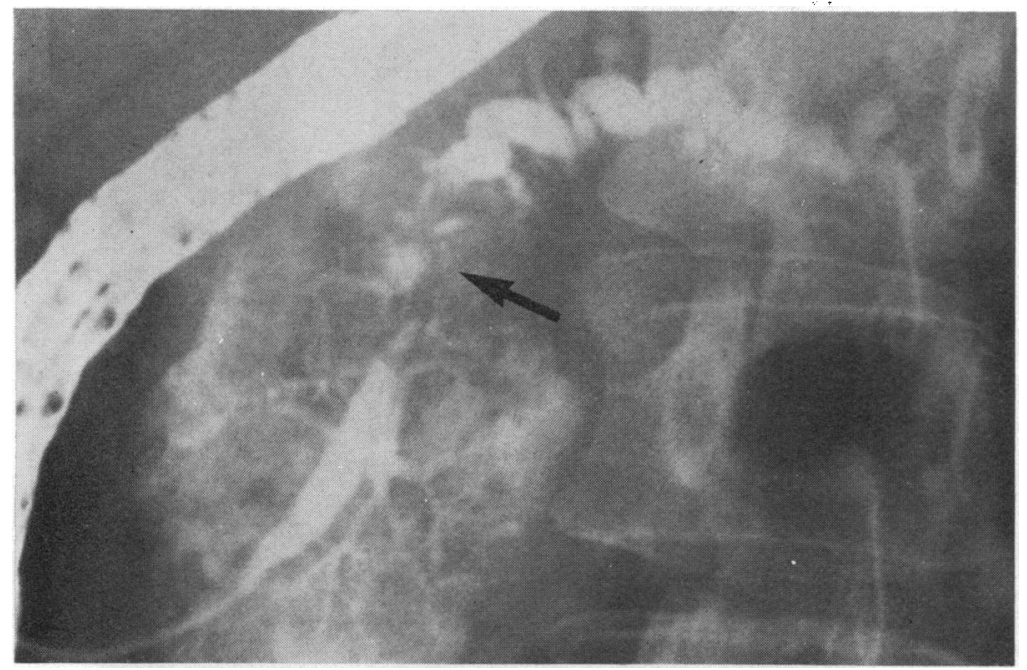

Fig. 4 A pancreatogram in a woman aged 55 years with pancreatic carcinoma. There is an irregular stenosis of the main pancreatic duct in the head of the pancreas (arrow) with dilatation of the main duct in the body. Fine acinar filling of the head of the pancreas has been produced by continued contrast injection.

three of the patients. In 15 of the 26 patients the biliary system was outlined and neoplastic involvement of the biliary system was demonstrated in 12 patients.

\section{CYTOLOGY FINDINGS}

Several types of morphologically distinct cells were seen in the pure pancreatic juice. Low columnar cells often arranged in clusters were present in all specimens. These were considered to be derived from the pancreatic duct (Fig. 5). In some patients there were cells with fragmented karryorhectic nuclei, the fragments arranged peripherally in a rather dense, usually eosinophilic cytoplasm; they appeared to be degenerate cells (Fig. 6). These cells were usually separate but occasionally lay in sheets.

Occasionally, goblet cells with a granular cytoplasm were present. Polymorphs and macrophages were occasionally seen but rarely in any great number. Malignant cells either separate or in clusters were found in some cases (Fig. 7). In patients where pure juice had been collected from the orifice of the papilla of Vater, cells from the dvodenal epithelium were seen and cells described as bile duct cells were also present.

\section{Normal group}

In these patients with no detectable pancreatic disease, normal duct cells were seen in all 26 patients. In four patients occasional degenerate cells were seen and in one patient these cells were present in moderate numbers.

\section{Pancreatic group}

Normal duct cells were seen in all nine patients in this group. In eight patients numerous degenerate cells were seen, but in one patient these cells were scanty.

\section{Pancreatic carcinoma}

Malignant cells were seen in 14 of the 26 patients in this group, in a further three patients the cytological findings were suspicious, and in the remaining nine patients no malignant cells were seen. In all the 26 patients in this group numerous degenerate cells were seen.

\section{COMBINED ERCP AND CYTOLOGY RESULTS}

The combined results in the 26 patients with pancreatic carcinoma are shown in Fig. 8. ERCP and cytology were both diagnostic in eight patients, ERCP was diagnostic in 10 patients when cytology was negative. There were six patients where the cannula could not be passed through the papilla of Vater and ERCP failed. Malignant cells were found in the pancreatic fluid aspirated from the papilla in all these six patients. At necropsy all these patients were found to have a pancreatic tumour obstructing the main pancreatic duct close to the papilla of Vater.

In only two of the patients with carcinoma were ERCP and cytology both negative.

ERCP alone was diagnostic in 18 patients $(65 \%)$, pure juice cytology alone was diagnostic in 14 patients $(54 \%)$; when the results of ERCP and cytology were combined a diagnostic result was obtained in 24 of the 26 patients $(92 \%)$. 


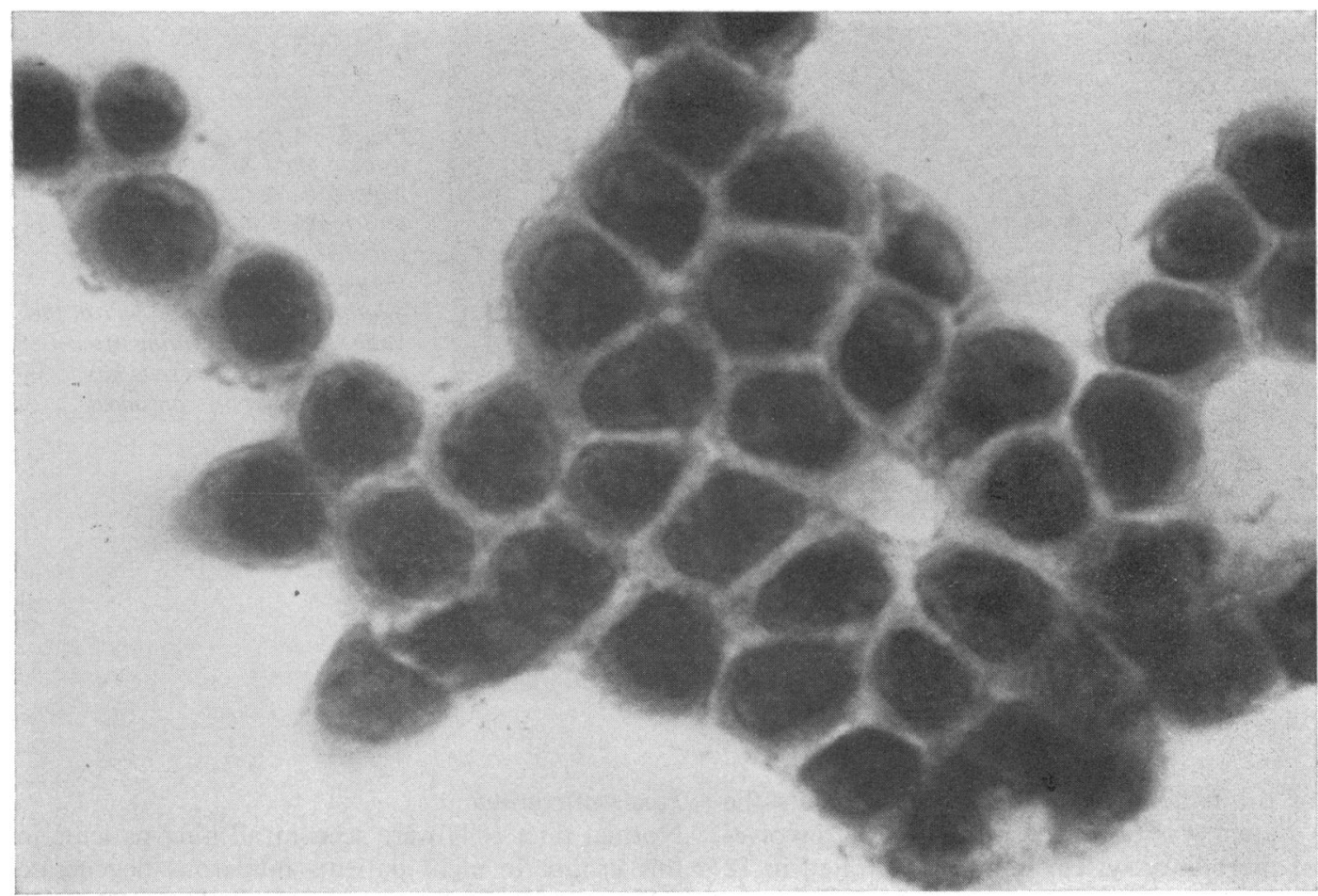

Fig. 5 Normal pancreatic duct cells. $\times 1250$.

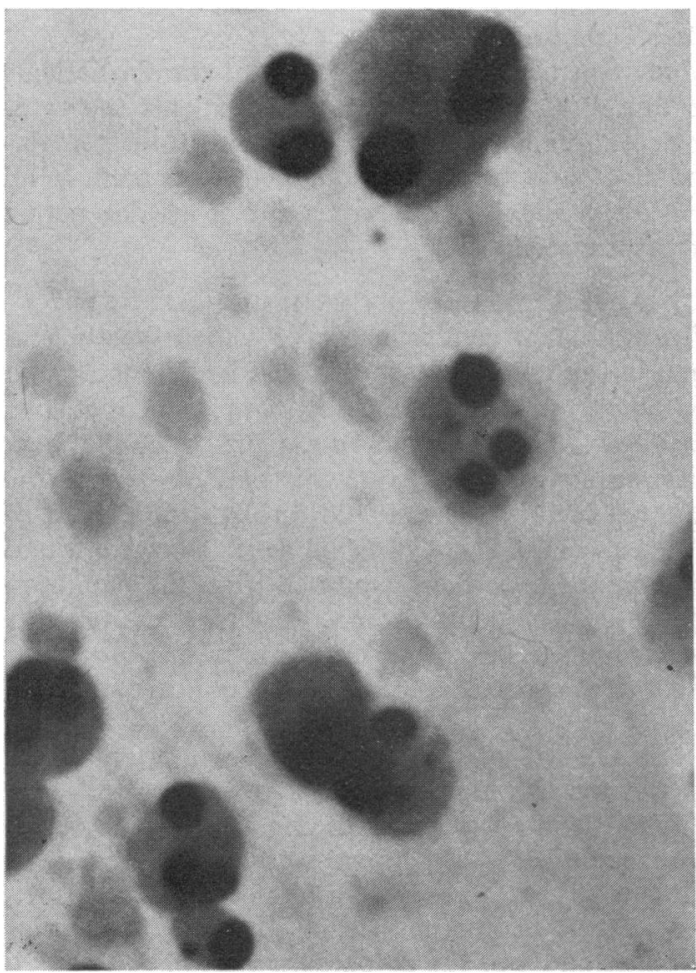

Fig. 6 Degenerate cells in pure pancreatic juice. The nuclei are fragmented and the cytoplasm is dense. $\times 1250$. 


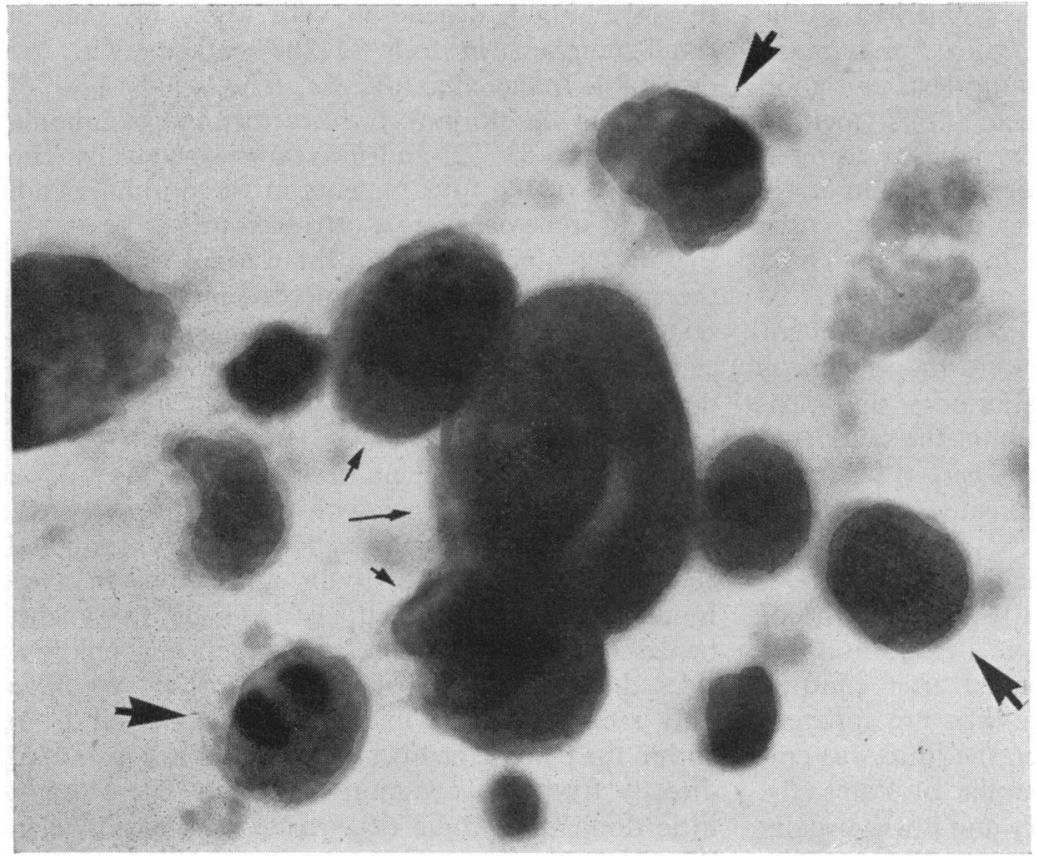

Fig. 7 A cluster of three malignant cells (small arrows) surrounded by degenerate cells (large arrows). $\times 1250$.

\begin{tabular}{llc|c} 
& \multicolumn{2}{c}{ ERCP Findings } \\
& & Positive & Negative \\
Pure Pancreatic & Positive & 8 & 6 \\
Juice Cytology & & & \\
\cline { 2 - 3 } & Negative & 10 & 2
\end{tabular}

Fig. 8 Combined ERCP and pure pancreatic juice cytology findings in 26 patients with pancreatic carcinoma.

\section{Discussion}

ERCP has been used in this country over the last four years and only slightly longer in Japan and Germany. In this short period of time it has been firmly established as a safe and practical way to examine the pancreatic and biliary duct systems in lightly sedated patients (Cotton, 1972; Cotton et al., 1972; Kasugai et al., 1972). However, as in any new technique, there can be considerable difficulty in the interpretation of some of the radiological findings, particularly with the pancreatogram. There are three main problems: failure to cannulate the papilla, making the radiological distinction between carcinoma and pancreatitis, and deciding what is minimal pancreatitis and what is a normal variant in the pancreatogram. Failure to introduce the cannula through the papilla of Vater does not necessarily indicate local obstructing pathology, although in this study it is of interest that pancreatic duct cannulation failed in eight of the total of 61 patients and that six of these eight patients proved to have a proximal pancreatic tumour obstructing the main pancreatic duct.

At times, marked narrowing of the main pancreatic duct with distortion of the side duct system can be produced both by pancreatitis and carcinoma, and the pancreatogram will not distinguish between them. There has been considerable debate as to the significance of small cystic dilatations of less than $2 \mathrm{~mm}$ and other minor side duct irregularities. Kasugai (1972) feels that they represent minimal change pancreatitis and has necropsy histological evidence to support this (Kasugai et al., 1973). Kreel and Sandin (1973), who have found such minor changes in a high percentage of post mortem pancreatograms in the over 60 years age group, have failed to find histological evidence of pancreatitis (Kreel $e t$ al., 1973), and feel these changes represent a normal ageing process. It seems likely that pure pancreatic juice cytology might help in these three difficult areas in pancreatography.

The cytological examination of duodenal aspirates was first reported by Lemon and Byrnes in 1949. They reported a $57 \%$ success in the detection of pancreatic carcinoma using no stimulus of pancreatic 
secretion. Since then, Raskin has commented on the increased cellular yield when a collection is made during a secretin-pancreatic function test, and good results have been reported using this method (Wenger and Raskin, 1958). Even when using a rapid method of duodenal intubation (Raskin et al., 1958), the technique of positioning a duodenal tube and collecting the aspirate is tedious and time consuming.

The enzymatic degeneration of the cell content occurs rapidly in duodenal juice and the specimens have to be delivered to the laboratory and processed immediately. Cells found in the duodenal aspirate may have derived from any part of the upper gastrointestinal tract and this can cause difficulty in interpretation.

In pure pancreatic juice the yield of cells is good, the morphology excellent, and their precise site of origin is known. There is no rapid deterioration of cells and if the juice were collected after contrast medium has been injected there was no apparent change in cell preservation. When the juice was collected from the orifice of the papilla of Vater, the morphology was quite satisfactory and it was usually possible to recognize duodenal epithelium as distinct from pancreatic in these specimens. The cytological aspects of pure pancreatic juice collection using the technique of ERCP was first reported by Kozu in 1972, and since then several authors have published results reporting cytodiagnostic success in pancreatic carcinoma varying between $50-79 \%$ (Kozu, 1972; Endo et al., 1974; Hatfield, et. al., 1974; Morii et al., 1974; Hatfield et al., 1975).

As amylasaemia is a relatively common occurrence after ERCP (Cotton, 1972; Kasugai et al., 1972), and as in a previous report (Hatfield et al., 1973) noticeable rises in serum amylase levels occurred in two patients when pancreatic juice was collected independently from ERCP, there is a potential risk in combining the two techniques. In this study, a mild elevation of serum amylase levels of up to 400 Somogyi units (normal $250 \mathrm{SU}$ ) was observed in two-thirds of the patients studied, although in two patients with complete main pancreatic duct obstruction the levels reached 1000 Somogyi units.

Transitory abdominal pain lasting a few minutes only was experienced by a few patients. In no patient was there severe or prolonged pain and the serum amylase fell to normal in all patients within 48 hours. By combining the two techniques, the patients underwent a single examination and with the sedative and amnesic advantages of intravenous diazepam the procedure was extremely well tolerated.

It is of interest that numerous degenerate pancreatic cells were seen in all the patients with pancreatic pathology, both inflammatory and neoplastic. On the other hand, degenerate cells were only seen in small numbers in four of the patients with no detectable pancreatic disease. The mean ages of patients in the normal, pancreatitis, and carcinoma groups were 63,52 , and 64 years respectively. The mean age of the four patients in the normal group who had some degenerate cells seen was 65 years. As there were nine patients in the normal groups over the age of 70 years in whom no degenerate cells were seen, it seems unlikely that the presence of degenerate cells in pancreatic juice is related to ageing. These degenerate cells with their characteristic morphology have been commented on by Henning and Witte in 1968, who described them in duodenal aspirates and associated their presence with chronic liver disease. Raskin et al. in 1958 thought they were epithelial cells of indeterminate origin and Gibbs in 1963 found them in bile-stained gastric lavage specimens, he described them as mercury droplet cells and considered that they were of duodenal origin. We have only seen such cells in pure juice collected from within the pancreatic duct and never in bile aspirated directly from the common bile duct. There seems little doubt that these degenerate cells originate in the pancreas.

The diagnosis and assessment of pancreatitis has always been difficult and ERCP has certainly allowed a diagnosis to be reached more easily. However, a normal pancreatogram does not exclude pancreatitis (Cotton and Beales, 1974), and it is difficult to know what interpretation to put on minimal changes in the pancreatogram. The cytological findings of degenerate cells in the pure juice may help in the interpretation of the pancreatogram, favouring a diagnosis of pancreatitis.

The incidence of pancreatic carcinoma appears to be rising (Krain, 1972), but the prognosis remains poor. Despite the wider use of ERCP in Japan, earlier diagnosis has not so far changed the incidence of operable tumours of the pancreas and survival is still poor. It seems unlikely that ERCP will radically alter the mortality of pancreatic carcinoma, as symptoms such as pain and jaundice that would alert the patient and clinician imply invasion by the pancreatic carcinoma.

Pure juice pancreatic cytology at the time of ERCP enhances the diagnostic accuracy of pancreatography, and in this study was of of particular importance where proximal pancreatic tumours made cannulation impossible. In the six patients where such tumours obstructed the pancreatic duct rendering ERCP impossible, the addition of pure juice cytology converted a negative investigation into a diagnostic one. It would seem, therefore, that the place of combined approach of ERCP and pure juice cytology in pancreatic carcinoma is to provide a 
rapid and safe preoperative diagnosis, thus reducing the time of inpatient stay and by-passing some of the numerous and more unpleasant investigations at present used in this condition.

\section{Conclusion}

Pure pancreatic juice can be conveniently collected at the time of ERCP and this juice is ideally suited for cytodiagnosis. The presence of typical degenerate cells in the pure juice appears to be related to the presence of pancreatic pathology and could be helpful in the distinction of minor inflammatory changes in the pancreatogram from a normal variant. The additional information provided by pure pancreatic juice cytology enhances the diagnostic accuracy of ERCP in pancreatic carcinoma and is of particular use in patients where ERCP has failed.

We would like to thank Miss Brenda Brown, FIMLT, and Mrs T. Deller, SRN, for their skilled technical assistance.

\section{References}

Cotton, P. B. (1972). Cannulation of the papilla of Vater by endoscopy and retrograde cholangiopancreatography (ERCP). Gut, 13, 1014-1025.

Cotton, P. B., and Beales, J. S. M. (1974). Endoscopic pancreatography in management of relapsing acute pancreatitis. British Medical Journal, 1, 608-611.

Cotton, P. B., Salmon, P. R., Blumgart, L. H., Burwood, R. J., Davies, G. T., Lawrie, B. W., Pierce, J. W., and Read, A. E. (1972). Cannulation of papilla of Vater via fiber-duodenoscope. Assessment of retrograde cholangiopancreatography in 60 patients. Lancet, 1, 53-58.

Endo, Y., Morii, T., Tamura, H., and Okuda, S. (1974). Cytodiagnosis of pancreatic malignant tumors by aspiration, under direct vision, using a duodenal fiberscope. Gastroenterology, 67, 944-951.

Gibbs, D. D. (1963). Degenerating cells in bile-stained gastric aspirates. Acta Cytologica, 7, 311-314.

Hatfield, A. R. W., Smithies, A., Wilkins, R., and Levi, A. J. (1975). Endoscopic retrograde cholangiopancreatography (ERCP) and pure pancreatic juice cytology: a combined diagnostic approach in pancreatic disease. Gut, 16, 405.
Hatfield, A. R. W., Whittaker, R., and Gibbs, D. D. (1974) The collection of pancreatic fluid for cytodiagnosis using duodenoscope. Gut, 15, 305-307.

Henning, N., and Witte, S. (1968). Atlas der gastroenterologischen Zytodiagnostik. 2nd edn, p. 21-22. Thieme: Stuttgart.

Kasugai, T., Kuno, N., and Kizu, M. (1973). Endoscopic pancreatocholangiography with special reference to manometric method. Medical Journal of Australia, 2, 717-725.

Kasugai, T., Kuno, N., Kizu, M., Kobayashi, S., and Hattori, K. (1972). Endoscopic pancreatocholangiography. II. The pathological endoscopic pancreatocholangiogram. Gastroenterology, 63, 227-234.

Kasugai, T., Kuno, N., Kobayashi, S., and Hattori, K. (1972). Endoscopic pancreatocholangiography. I. The normal endoscopic pancreatocholangiogram. Gastroenterology, 63, 217-226.

Kozu, T. (1972). Duodenoscopic collection of intraductal pure pancreatic juice and its application to the cytodiagnosis. In Endoscopy of the Small Intestine with Retrograde Pancreatocholangiography. International Workshop at Erlamgen, 1972. Thieme: Stuttgart.

Krain, L. S. (1972). Cancer incidence: the crossing of curves for stomach and pancreatic cancer. Digestion, 6, 356-366.

Kreel, L., and Sandin, B. (1973). Changes in pancreatic morphology associated with aging. Gut, 14, 962-970.

Kreel, L., Sandin, B., and Slavin, G. (1973). Pancreatic morphology: a combined radiological and pathological study. Clinical Radiology, 24, 154-161.

Lemon, H. M., and Byrnes, W. W. (1949). Cancer of the biliary tract and pancreas. Diagnosis from cytology of duodenal aspirations. Journal of the American Medical Association, 141, 254-257.

Morii, T., Endo, Y., Ebara, M., Tatsuta, M., Okuda, S., and Tamura, H. (1974). Diagnosis of pancreatic cancer by pancreatography and cytology with duodenal fiberscope. Abstracts of XIth International Cancer Congress, Florence. Excerpta Medica: Amsterdam.

Raskin, H. F., Wenger, J., Sklar, M., Pleticka, S., and Yarema, W. (1958). The diagnosis of cancer of the pancreas, biliary tract, and duodenum by combined cytologic and secretory methods. I. Exfoliative cytology and a description of a rapid method of duodenal intubation. Gastroenterology, 34, 996-1008.

Wenger, J., and Raskin, H. F. (1958). The diagnosis of cancer of the pancreas, biliary tract, and duodenum by combined cytologic and secretory methods. II. The secretin test. Gastroenterology, 34, 1009-1017. 